\title{
Objawy związane z idiopatyczną nietolerancją środowiskową przypisywaną działaniu pól elektromagnetycznych (IEI-EMF) - badanie kwestionariuszowe
}

\begin{abstract}
The aim of the study was to analyse the symptoms reported by self-reported IEI-EMF subjects with the use of web-based questionnaire. 408 potentially electrosensitive individuals were identified and symptoms reported by them were analysed and compared depending on demographic characteristics. Declared symptoms were usually not specific and difficult for an objective medical assessment, what is in line with results of previous studies. (Symptoms related to idiopathic environmental intolerance attributed to electromagnetic fields (IEI-EMF) - a questionnaire study)

Streszczenie. Badanie miało na celu analizę objawów związanych ze zjawiskiem idiopatycznej nietolerancji środowiskowej przypisywanej działaniu pola elektromagnetycznego. Zostało ono przeprowadzone z zastosowaniem metody ankietowej. Objawy zgłaszane przez 408 potencjalnie elektrowrażliwych respondentów zostały przeanalizowane i porównane w odniesieniu do danych demograficznych. Zgłaszane objawy były zwykle niespecyficzne i trudne do obiektywnej oceny, co potwierdza wyniki wcześniej przeprowadzonych badań.
\end{abstract}

Keywords: idiopathic environmental intolerance, electromagnetic fields,, electrosensitivity, questionnaire studies Słowa kluczowe: idiopatyczna nietolerancja środowiskowa, pola elektromagnetyczne, elektrowrażliwość, badania ankietowe

\section{Wstęp}

Potencjalny wpływ pola elektromagnetycznego (PEM) pochodzącego $z$ różnorodnych źródeł na zdrowie jest tematem kontrowersyjnym i szeroko dyskutowanym. Dotychczas analizowano różnorodne potencjalne skutki długotrwałego narażenia na PEM, w szczególności wpływ na centralny system nerwowy, występowanie nowotworów głowy i szyi, zaburzenia reprodukcyjne czy immunologiczne, jak dotąd jednak nie przedstawiono przekonywujących dowodów wspierających tezę o szkodliwości PEM z zakresu częstotliwości radiowych [1] Jedną z postulowanych, potencjalnych manifestacji wpływu PEM na zdrowie jest idiopatyczna nietolerancja środowiskowa przypisywana działaniu PEM (ang. idiopathic environmental intolerance attributed to electromagnetic fields, IEI-EMF), zwana również nadwrażliwością elektromagnetyczną (ang. electromagnetic hypersensitivity) [2].

IEI-EMF polega na występowaniu niespecyficznych objawów u osób określających się jako elektrowrażliwe (OE), które przypisywane są przez nie ekspozycji na PEM pochodzące $z$ różnorodnych źródeł [3]. Pomimo doniesień o częstości tego zjawiska sięgającej nawet $13 \%$ w niektórych populacjach [4], wciąż brakuje jednolitych kryteriów rozpoznania tego schorzenia, co powoduje znaczne rozbieżności w doniesieniach naukowych. Dwoje francuskich badaczy, Belpomme oraz Irrigay [5], zaproponowało następujące kryteria rozpoznania: (1) brak znanej patologii odpowiadającej za występowanie odczuwanych objawów, (2) występowanie niespecyficznych objawów fizykalnych, takich jak ból głowy, szumy uszne, przeczulica słuchowa, zawroty głowy, zaburzenia pamięci krótkotrwałej, problemy z koncentracją/uwaga, (3) odtwarzalność objawów pod wpływem PEM, (4) ustąpienie bądź złagodzenie objawów w przypadku unikania ekspozycji na PEM, (5) podobieństwo do mnogiej nadwrażliwości na czynniki chemiczne (multiple chemical sensitivity - MCS). Nie są one jednak jeszcze powszechnie stosowane, a samo schorzenie budzi nadal poważne kontrowersje.

\section{Cel badania}

Głównym celem badania była analiza zależności objawów zgłaszanych przez OE, które w ich ocenie są następstwem ekspozycji na PEM, od charakterystyki demograficznej respondentów. Drugorzędowym celem było podsumowanie i omówienie danych dotyczących objawów występujących u OE, które dostępne są w literaturze międzynarodowej.

\section{Materiały i metody}

Przekrojowe badanie kwestionariuszowe, mające na celu analizę grupy OE w populacji polskiej, zostało przeprowadzone za pomoca formularza internetowego. Przedstawiane wyniki są elementem większego projektu, analizującego wiedzę populacji polskiej na temat wpływu PEM na zdrowie.

Kryteriami włączenia był wiek powyżej 16 lat, znajomość języka polskiego umożliwiająca zrozumienie treści pytań oraz poprawne wypełnienie całości kwestionariusza. W przypadku niejasnej, bądź niepełnej odpowiedzi na którekolwiek pytanie, wszystkie dane respondenta były wykluczane $z$ analizy.

\section{Kwestionariusz}

Kwestionariusz składał się 32 pytań. Część z nich obejmowała dane demograficzne (rok urodzenia, płeć, kod pocztowy miejsca pracy i zamieszkania, odległość miejsca zamieszkania od najbliższej stacji bazowej telefonii komórkowej (SBTK), ocena stanu zdrowia (choroby przewlekłe, przyjmowane leki, przebyte schorzenia i zabiegi operacyjne). Część pytań miała na celu określenie potencjalnej elektrowrażliwości badanych.

Tabela 1. Lista objawów wymienionych $w$ ankiecie możliwych do wyboru jako skutek ekspozycji na PEM.

arytmia, bezsenność, ból głowy, ból oczy, ból stawów, ból ucha, chrypka, duszności, kaszel, katar, kłopoty z uczeniem się, kołatanie serca, łzawienie, niepokój, nieprzyjemne wrażenia słuchowe, nieprzyjemne wrażenie wzrokowe, obniżone ciśnienie, obniżone tętno, obrzęk, podwyższone ciśnienie, podwyższone tętno, problemy z zasypianiem, rozdrażnienie, senność, suchość w ustach, swędzenie, trudności w wysławianiu się, trudności z koncentracją, wybudzenia nocne, wysypka, zaczerwienie skóry, zmęczenie

Uczestnicy byli klasyfikowani jako OE jeśli odpowiedzieli twierdząco na pytanie "Czy urządzenia elektryczne / elektroniczne / telekomunikacyjne wpływają niekorzystnie na Pani/Pana samopoczucie?" i zaznaczyli co najmniej 
jedno urządzenie, które w ich ocenie wpływa na nich negatywnie. Badany miał możliwość wskazania obserwowanych u siebie objawów przypisywanych PEM (Tabela 1) oraz oceny ich nasilenia w 6-stopniowej skali (od 0 do 5).

\section{Analiza statystyczna}

Analiza statystyczna została przeprowadzona za pomocą programu Statsoft STATISTICA 13.3. Podgrupy dla porównań zostały wyodrębnione na podstawie danych demograficznych: płci (kobiety vs. mężczyźni), wieku (<33 lat vs. $\geq 33$ lat, na podstawie mediany dla całej grupy badanych), miejsca zamieszkania (miejskie vs. pozamiejskie, analizowane na podstawie danych geolokalizacyjnych lub kodów pocztowych) oraz raportowanej odległości miejsca zamieszkania od najbliższej stacji bazowej telefonii komórkowej (<1500 vs. $\geq$ 1500 metrów). Porównania zmiennych jakościowych przeprowadzane były za pomocą testu $\mathrm{chi}^{2}, \mathrm{z}$ odpowiednimi poprawkami. Normalność rozkładu zmiennych ciągłych potwierdzana była testem Shapiro-Wilka. Zmienne ciągłe porównywane były testem t-Studenta lub Manna-Whitneya, w zależności od normalności rozkładu. Wartość $p<0,05$ uznawana była za punkt odcięcia dla wyników istotnie statystycznych.

\section{Przegląd literatury}

Anglojęzyczne publikacje opisujące częstość poszczególnych objawów u OE zostały zidentyfikowane w bazach danych MEDLINE / PubMed / ScienceDirect. Poszukiwano artykułów zawierających wyrażenia „electrosensitive subjects”, „electrohypersensitivity”, „IElEMF" i pochodnych. Bibliografie zakwalifikowanych publikacji zostały również przeszukane ręcznie. W celu poprawy czytelności wyników i wniosków objawy zostały pogrupowane w kilka odrębnych kategorii. W przypadku gdy badanie uwzględniało więcej niż jeden objaw $z$ danej kategorii w tabeli zbiorczej uwzględniany był tylko najczęściej występujący objaw.

\section{Wyniki}

Badanie kwestionariuszowe

Spośród 1028 respondentów, którzy poprawnie wypełnili cały kwestionariusz, 408 zostało zaklasyfikowanych jako OE. Niemal $71 \%(288)$ tej grupy stanowiły kobiety. Średnia wieku całej grupy wyniosła 33 lata $( \pm 15)$. Większość nie cierpiała na żadną chorobę przewlekłą $(287,70,3 \%)$ i żyła na terenie wysoce zurbanizowanym (297, 72,8\%). Wśród wskazywanych chorób najczęściej występowały alergie (66, $16,2 \%)$, nadciśnienie tętnicze $(47,11,5 \%)$ oraz choroby skóry $(43,10,5 \%)$.

Najczęściej wskazywane objawy związane z ekspozycją na PEM to zmęczenie (326, 79,9\%), ból głowy (303, 74,3\%) oraz ból oczu $(278,68,2 \%)$. Ponadto, innymi często wskazywanymi symptomami były rozdrażnienie (269, $65,9 \%)$, trudności z koncentracją $(261,64,0 \%)$, problemy z zasypianiem (166, 40,7\%), niepokój (151, 37,0\%), senność $(130,31,9 \%)$ i wybudzanie ze snu $(114,27,9 \%)$. Stars respondenci zgłaszali więcej objawów w porównaniu do młodszych (młodsi vs. starsi; średnia \pm SD: $6,6 \pm 3,3$ vs. 8,0 $\pm 4,2 ; p<0,01)$ i częściej wiązali rozdrażnienie $(p<0,01)$ niepokój $(p<0,01)$, objawy laryngologiczne $(p<0,01)$, nieprzyjemne wrażenia słuchowe $(p=0,01)$, dolegliwości sercowo-naczyniowe $(p<0,01)$, nieprzyjemne wrażenia słuchowe $(p<0,01)$, ból stawów $(p<0,01)$, bóle kostne $(p<0,01)$, ból uszu $(p<0,01) z$ ekspozycją na PEM. Młodsi uczestnicy natomiast częściej wskazywali ból głowy $(p=0,03)$, ból oczu $(p<0,01)$ i senność $(p=0,02)$ (Tabela 2$)$. Mężczyźni w porównaniu do kobiet istotnie częściej skarżyli się na ból oczu (mężczyźni vs. kobiety; $45,0 \%$ vs. 26,4\%, p $<0,01)$ w efekcie ekspozycji na PEM.
Tabela 2. Objawy zgłaszane przez respondentów, oraz wyniki analizy częstości ich występowania w zależności od wieku.

\begin{tabular}{|c|c|c|c|c|}
\hline \multirow{2}{*}{ Objaw } & \multirow{2}{*}{$\begin{array}{c}\mathrm{N} \\
\text { zgłaszających } \\
\text { respondentów } \\
(\%)\end{array}$} & \multicolumn{2}{|c|}{$\begin{array}{l}\text { \% respondentów } \\
\text { w grupie }\end{array}$} & \multirow{2}{*}{$p$} \\
\hline & & $<33$ lat & $\geq 33$ lat & \\
\hline Zmęczenie & $326(79,9 \%)$ & 80,1 & 79,7 & $>0,05$ \\
\hline Ból głowy & $303(74,3 \%)$ & 79,1 & 69,8 & 0,03 \\
\hline Ból oczu & $278(68,1 \%)$ & 76,0 & 60,8 & $<0,01$ \\
\hline $\begin{array}{l}\text { Problemy z } \\
\text { koncentracją }\end{array}$ & $270(66,2 \%)$ & 68,9 & 63,7 & $>0,05$ \\
\hline Nerwowość & $269(65,9 \%)$ & 56,6 & 74,5 & $<0,01$ \\
\hline $\begin{array}{l}\text { Problemy ze } \\
\text { snem }\end{array}$ & $215(52,7 \%)$ & 51,0 & 54,2 & $>0,05$ \\
\hline Niepokój & $151(37,0 \%)$ & 24,0 & 49,1 & $<0,01$ \\
\hline Senność & $130(31,9 \%)$ & 37,2 & 26,9 & 0,02 \\
\hline $\begin{array}{l}\text { Objawy } \\
\text { laryngologiczne }\end{array}$ & $125(30,6 \%)$ & 21,4 & 39,2 & $<0,01$ \\
\hline $\begin{array}{l}\text { Objawy } \\
\text { sercowo- } \\
\text { naczyniowe }\end{array}$ & $113(27,7 \%)$ & 17,9 & 36,8 & $<0,01$ \\
\hline $\begin{array}{l}\text { Nieprzyjemne } \\
\text { wrażenia } \\
\text { wzrokowe lub } \\
\text { słuchowe }\end{array}$ & $112(27,5 \%)$ & 20,4 & 34,0 & $<0,01$ \\
\hline Ból stawów & $74(18,1 \%)$ & 12,2 & 23,6 & $<0,01$ \\
\hline $\begin{array}{l}\text { Problemy } \\
\text { skórne }\end{array}$ & $51(12,5 \%)$ & 3,6 & 20,8 & $<0,01$ \\
\hline Ból uszu & $46(11,3 \%)$ & 5,6 & 16,5 & $<0,01$ \\
\hline
\end{tabular}

Nasilenie dolegliwości najczęściej określane było na 3 w sześcio-stopniowej skali $(192,47,1 \%)$ i było ono istotnie większe pośród starszych ankietowanych $(p=0,01)$. Starsi ankietowani zgłaszali także większą ilość objawów w porównaniu do młodszych (młodsi vs. starsi, średnia \pm SD: $6,6 \pm 3,3$ vs. $8,0 \pm 4,2, p=0,01$ ). Dane dotyczące nasilenia $i$ liczby objawów podsumowane są w Tabeli 3.

Tabela 3. Nasilenie oraz liczba zgłaszanych objawów przez osoby elektrowrażliwe w podgrupach (pogrubiono różnice istotne statystycznie).

\begin{tabular}{|l|c|c|}
\hline & $\begin{array}{c}\text { Nasilenie } \\
\text { objawów } \\
\text { (średnia } \pm \text { SD) }\end{array}$ & $\begin{array}{c}\text { Liczba } \\
\text { zgłaszanych } \\
\text { objawów } \\
\text { (średnia } \pm \text { SD) }\end{array}$ \\
\hline $\begin{array}{l}\text { Grupa } \\
\text { wiekowa }\end{array}$ & \\
\hline$<33$ lat & $\mathbf{2 , 8} \pm \mathbf{0 , 8}$ & $\mathbf{6 , 6 \pm \mathbf { 3 , 3 }}$ \\
\hline$\geq 33$ lat & $\mathbf{3 , 1} \pm \mathbf{1 , 0}$ & $\mathbf{8 , 0} \pm \mathbf{4 , 2}$ \\
\hline Płeć & $2,8 \pm 0,9$ & $7,2 \pm 3,7$ \\
\hline Mężczyźni & $3,0 \pm 0,9$ & $7,4 \pm 3,9$ \\
\hline Kobiety & & \\
\hline $\begin{array}{l}\text { Miejsce } \\
\text { zamieszkania }\end{array}$ & $3,0 \pm 1,0$ & $7,6 \pm 4,2$ \\
\hline Wieś & $2,9 \pm 0,9$ & $7,2 \pm 3,7$ \\
\hline Miasto & & \\
\hline $\begin{array}{l}\text { Odległość od } \\
\text { SBTK }\end{array}$ & $3,0 \pm 0,9$ & $7,6 \pm 4,4$ \\
\hline$<1500 \mathrm{~m}$ & $2,9 \pm 0,9$ & $7,2 \pm 3,7$ \\
\hline$\geq 1500 \mathrm{~m}$ & \multicolumn{2}{|l}{} \\
\hline
\end{tabular}

\section{Analiza literatury}

Wykorzystując metodologię przeglądu literatury zidentyfikowano 10 badań opisujących częstość występowania objawów w populacjach OE. Badania były przeprowadzone w latach 2002-2017, w większości w Europie Zachodniej i Azji. Wszystkie badania przeprowadzone były za pomocą ankiet, a objawy były zgłaszane bezpośrednio przez pacjentów. Szczegóły dotyczące danych uzyskanych z poszczególnych badań zawarte są w Tabeli 4. 
Tabela 4. Objawy zgłaszane przez pacjentów IEI-EMF według międzynarodowej literatury

\begin{tabular}{|c|c|c|c|c|c|c|c|c|c|c|c|}
\hline \multirow{2}{*}{ Badanie } & \multirow{2}{*}{ Kraj } & \multirow{2}{*}{$\stackrel{N}{\text { N }}$} & \multicolumn{9}{|c|}{$\begin{array}{c}\text { Objawy ekspozycji na PEM u osób IEI-EMF+ } \\
\text { [\% grupy IEI-EMF] }\end{array}$} \\
\hline & & & $3>$ & 03 & 03 & $>N$ g & $E>\mathbb{N}$ & $\circlearrowright \subsetneq$ & $E>\frac{0}{7}$ & 兰里 & $-\varepsilon$ \\
\hline bieżące badanie & Polska & 408 & 74,3 & & 18,1 & 79,9 & 40,7 & 63,9 & 18,1 & 14,2 & 8,6 \\
\hline Andrianome2017 [10] & Francja & 52 & 51,9 & 26,9 & 44,2 & 76,9 & 67,3 & 57,7 & 40,4 & 26.9 & 46,2 \\
\hline Gruber2018 [15] & Szwecja & 91 & 9,9 & & 25,3 & 17,6 & & & & & \\
\hline Hagström2012 [9] & Finlandia & 194 & 43,8 & 54,6 & 58,2 & 60,3 & 59,3 & 56,7 & & 48,5 & 55,2 \\
\hline Johansson2010 [8] & Szwecja & 71 & 73 & 75 & 79 & 92 & 65 & 81 & 66 & & 90 \\
\hline Kato2012 [7] & Japonia & 75 & 81,3 & 64 & 56 & 85,3 & 76 & 81,3 & 64 & & \\
\hline Kjellqvist2016 * [11] & Szwecja & 114 & 45,6 & 36 & 34,2 & 58,8 & 25,4 & 39,5 & 67,5 & & 43 \\
\hline Röösli2004 [12] & Szwajcaria & 394 & 41 & & & 18 & 58 & 16 & & & \\
\hline Röösli2010 [6] & Szwajcaria & 130 & & & & 59 & 34 & & 12 & & \\
\hline Stenberg2002 [13] & Szwecja & 50 & 22 & & & 32 & & 12 & & 26 & 38 \\
\hline van Dongen2014 [14] & Holandia & 212 & 2,5 & 16,7 & 5,8 & 5,2 & & & & 16,7 & \\
\hline
\end{tabular}

\section{Dyskusja}

Przeprowadzone badanie pokazuje jakie dolegliwości wiązane są $z$ ekspozycją na promieniowanie elektromagnetyczne przez OE. Wśród zgłaszanych objawów wyraźnie dominuja te niespecyficzne, trudne do obiektywnej oceny przez lekarza. Najczęściej zgłaszane objawy to zmęczenie, ból głowy, ból oczu, problemy z koncentracją, nerwowość, problemy ze snem. Osoby starsze zgłaszały większą ilość objawów związanych z ekspozycją na PEM, a także skarżyły się na dłużej trwające dolegliwości, w porównaniu do grupy młodszych respondentów. Nie odnotowano znaczących różnic w zgłaszanych objawach i ich nasileniu pomiędzy kobietami a mężczyznami, a także poza osobami zamieszkującymi lub pracującymi na terenach miejskich i pozamiejskich.

Analiza dostępnej literatury dotyczącej zagadnienia IEIEMF wskazuje, że objawy zgłaszane przez pacjentów znacząco różnią się zarówno pomiędzy badanymi populacjami, jak i pomiędzy poszczególnymi pacjentami, jednak wciąż pozostają objawami niespecyficznymi. Zależnie od badania, najczęściej zgłaszanymi objawami przez OE są problemy z nastrojem (bieżące badanie, [611]), problemy ze snem [12], problemy dermatologiczne [13] lub bóle stawowo-mięśniowe [14,15]. W badaniach innych autorów raportowane były także objawy nie zgłaszane przez naszych respondentów, takie jak zawroty głowy (obecne nawet u $75 \%$ respondentów w szwedzkim badaniu [8]) lub zaburzenia pamięci. Występujące różnice wynikać mogą $z$ różnic $w$ metodologiach ankiet (objawy wskazywane $z$ listy vs. objawy podawane samodzielnie przez badanych), a także urządzeń postrzeganych przez badanych jako źródło objawów.

\section{Wnioski}

Objawy zgłaszane przez OE są zwykle niespecyficzne i trudne dla obiektywnej oceny przez lekarza. OE zgłaszają różnorodne dolegliwości, różniące się zarówno pomiędzy poszczególnymi uczestnikami badania, jak i całymi badanymi populacjami. Przyszłe badania powinny skupić się na szczegółowej analizie zgłaszanych objawów z towarzyszącą obiektywną oceną narażenia na źródła PEM.

\section{Autorzy}

lek. Artur Kacprzyk, Zakład Biofizyki, Katedra Fizjologii, Wydział Lekarski, Uniwersytet Jagielloński Collegium Medicum, ul. Św. Łazarza 16, 31-530 Kraków oraz Szkoła Doktorska Nauk Medycznych i Nauk o Zdrowiu UJ CM, ul. Św. Anny 12, 31-008 Kraków, E-mail: artur.kacprzyk@doctoral.uj.edu.pl; Gabriela Kanclerz, Studenckie Koło Naukowe Biofizyki Medycznej UJ CM, ul. Św. Łazarza 16, 31-530 Kraków, e-mail: gabriela.kanclerz@student.uj.edu.pl; Urszula Sołdaj, j.w., urszula.soldaj@student.uj.edu.pl; dr Bartosz Lisowski, Zakład Biofizyki, Katedra Fizjologii, Wydziat Lekarski, Uniwersytet Jagielloński Collegium Medicum, ul. Św. Łazarza 16, 31-530 Kraków. e-mail: bartek.lisowski@uj.edu.pl; prof.dr hab. Eugeniusz Rokita, j.w., e-mail: e.rokita@uj.edu.pl; dr hab. Grzegorz Tatoń, j.w., e-mail: g.taton@uj.edu.pl

\section{LITERATURA}

1. Simkó M, Mattsson M-O. 5G Wireless Communication and Health Effects-A Pragmatic Review Based on Available Studies Regarding 6 to $100 \mathrm{GHz}$. Int. J. Environ. Res. Public Health 2019 Sep;16(18). DOI 10.3390/ijerph16183406

2. World Health Organization. Establishing a Dialogue on Risks from Electromagnetic Fields [Internet]. WHO Libr. Geneva, Switzerland; 2002. Available from: http://www.who.int/pehemf/publications/riskenglish/en/

3. WHO. Fact Sheet: Electromagnetic fields and public health [Internet]. 2005. Available from: https://www.who.int/pehemf/publications/facts/fs296/en/

4. Huang P-C, Cheng M-T, Guo H-R. Representative survey on idiopathic environmental intolerance attributed to electromagnetic fields in Taiwan and comparison with the international literature. Environ. Health England; 2018 Jan;17(1):5. DOI 10.1186/s12940-018-0351-8

5. Belpomme D, Irigaray P. Electrohypersensitivity as a Newly Identified and Characterized Neurologic Pathological Disorder: How to Diagnose, Treat, and Prevent It. Int. J. Mol. Sci. Switzerland; 2020 Mar;21(6). DOI 10.3390/ijms21061915 
6. Röösli M, Mohler E, Frei P. Sense and sensibility in the context of radiofrequency electromagnetic field exposure. Comptes Rendus Phys. 2010;11(9):576-84.

7. Kato $Y$, Johansson $O$. Reported functional impairments of electrohypersensitive Japanese: A questionnaire survey. Pathophysiol. Off. J. Int. Soc. Pathophysiol. Netherlands; 2012 Apr;19(2):95-100. DOI 10.1016/j.pathophys.2012.02.002

8. Johansson A, Nordin S, Heiden M, Sandström M. Symptoms, personality traits, and stress in people with mobile phonerelated symptoms and electromagnetic hypersensitivity. J. Psychosom. Res. England; 2010 Jan;68(1):37-45.

9. Hagström M, Auranen J, Ekman R. Electromagnetic hypersensitive Finns: Symptoms, perceived sources and treatments, a questionnaire study. Pathophysiol. Off. J. Int. Soc. Pathophysiol. Netherlands; 2013 Apr;20(2):117-22. DOI 10.1016/j.pathophys.2013.02.001

10. Andrianome S, De Seze R, Braun A, Selmaoui B. Descriptive self-reporting survey of people with idiopathic environmental intolerance attributed to electromagnetic fields (IEI-EMF): similarities and comparisons with previous studies. J. Public Health (Bangkok). 2018;26(4):461-73.

11. Kjellqvist A, Palmquist E, Nordin S. Psychological symptoms and health-related quality of life in idiopathic environmenta intolerance attributed to electromagnetic fields. J. Psychosom. Res. 2016/03/10. England; 2016 May;84:8-12.

12. Röösli M, Moser M, Baldinini $Y$, Meier $M$, Braun-Fahrländer $C$. Symptoms of ill health ascribed to electromagnetic field exposure--a questionnaire survey. Int. J. Hyg. Environ. Health. Germany; 2004 Feb;207(2):141-50.

13. Stenberg B, Bergdahl J, Edvardsson B, Eriksson N, Lindén G, Widman L. Medical and social prognosis for patients with perceived hypersensitivity to electricity and skin symptoms related to the use of visual display terminals. Scand. J. Work. Environ. Health Finland; 2002 Oct;28(5):349-57. DOI $10.5271 /$ sjweh. 685

14. van Dongen D, Smid T, Timmermans DRM. Symptom attribution and risk perception in individuals with idiopathic environmental intolerance to electromagnetic fields and in the general population. Perspect. Public Health 2013/08/02. United States; 2014 May;134(3):160-8.

15. Gruber MJ, Palmquist E, Nordin S. Characteristics of perceived electromagnetic hypersensitivity in the general population. Scand. J. Psychol. John Wiley \& Sons, Ltd (10.1111); 2018 Aug 1;59(4):422-7. Available from: https://doi.org/10.1111/sjop.12449 